\title{
REMOA
}

\section{EDUCAÇÃO AMBIENTAL NO CENTRO DE CIÊNCIAS RURAIS DA UFSM}

\author{
Lenise Schröder Boemo, Clayton Hillig
}

\section{RESUMO}

Devido às grandes desigualdades na distribuição da renda mundial, é provável que as camadas sociais economicamente desfavorecidas não tenham acesso aos alimentos em quantidade qualidade necessários para a manutenção de suas exigências nutricionais diárias. Há a necessidade de um crescimento sustentado da produção de alimentos, sob pena de o homem comprometer ainda mais o ecossistema. A Educação Ambiental (EA), quando situada em um amplo contexto, o da educação para a cidadania de pessoas preocupadas com o meio ambiente e com a sustentabilidade dos ecossistemas, configura-se como elemento importante para a consolidação da formação de sujeitos cidadãos e, certamente a Educação Ambiental é um dos melhores instrumentos para colocar em prática as mudanças de comportamento, que irão contribuir para a preservação do meio ambiente e manter a qualidade de vida. Este estudo teve por objetivo, identificar como a EA vem sendo tratada em suas diferentes formas no Centro de Ciências Rurais(CCR) da Universidade Federal de Santa Maria com uma abordagem focada para o curso de Zootecnia. A pesquisa foi desenvolvida com a utilização de instrumentos qualitativos e quantitativos de coleta de dados, reunindo características de cunho exploratório e descritivo, para mensurar como a EA esta inserida no CCR da UFSM, apontando condições, desafios e perspectivas para a ampliação de sua inserção na educação profissional. Com esse estudo houve a possibilidade de verificar como a EA está presente no Centro de CCR da UFSM. Foi possível constatar que há várias vertentes ligadas a EA no CCR as quais levam sob as diferentes perspectivas a educação ambiental ao CCR. E possível vislumbrar que havendo a ligação entre a educação formal, não formal e educação informal o somatório representa um saldo satisfatório da EA no CCR. Mas para isso, é necessário que as vertentes já existentes se expandam, que surjam novas iniciativas voltadas para a EA e que ocorra uma valorização da EA nos currículos dos cursos pertencentes ao CCR.

Palavras-chave: educação ambiental,centro de ciências rurais, educação formal, não formal e informal

\section{ENVIRONMENTAL EDUCATION IN THE RURAL SCIENCE CENTER AT UFSM}

ABSTRACT: Due to great inequality in the distribution of the world income, it is possible that the social classes economically disfavored do not have access to foods in quantity and quality necessary to maintain their daily nutritional demands. There is the necessity of sustainable growth in the production of foods, under penalty of compromising the ecosystem even more. Environmental Education (EE), when situated in a broad context, the one of education for citizenship of people worried about environment and sustainability of ecosystems, constitutes of an important element to consolidate the development of real citizens and, certainly Environmental Education is one of the best tools to put into practice the changes in behavior, which will contribute to the preservation of environment and maintain life quality. The objective of this study was to identify how EE has been treated in its different forms in the Rural Science Center (CCR) of the Federal University of Santa Maria with an approach focused on the course of Zootechny. The research was developed 


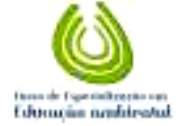

BOEMO \& HILIG, vol.(4), n4, p. 616-628, 2011. Monografias Ambientais

(e-ISSN: 2236-1308)

REMOA

with the use of qualitative and quantitative tools of data collection, gathering characteristics of exploratory and descriptive nature to measure how EE is inserted in the CCR at UFSM, pointing conditions, challenges and perspectives to the amplification of its inclusion in the professional education. With this study there was the possibility of verifying how EE is present in the CCR at UFSM. It was possible to establish that there are many ways connected to the EE in the CCR, those which take environmental education to CCR under different perspectives. It is possible to glimpse that if there is the relation between formal education, non-formal and informal education, the totality represents a satisfactory balance of EE in the CCR. For that, however, it is necessary that the already existing aspects expand, new initiatives aimed at EE appear, and that there is a valorization of EE in the curricula of the courses belonging to CCR.

Keywords: environmental education, rural science center, formal, non formal and informal education

\section{INTRODUÇÃO}

Considerando as grandes desigualdades na distribuição da renda mundial, é provável que as camadas sociais economicamente desfavorecidas não tenham acesso aos alimentos em quantidade e qualidade necessária para a manutenção de suas exigências nutricionais diárias.

Para a manutenção dos índices elevados de produção, principalmente na área de produção animal e vegetal, houve ao longo dos anos muitas evoluções, uma delas é a capacitação de profissionais das ciências rurais ou da terra. Os sistemas de produção modernos se beneficiam da utilização de tecnologias, em sua maioria com bases químicas. Esses produtos afetam o equilíbrio do meio ambiente e a manutenção dos ecossistemas, por meio de seus efeitos residuais sobre os demais organismos naturais.

A natureza vem demonstrando os abusos cometidos pela exploração humana aos recursos naturais na busca de recursos econômicos e poder. Essas demonstrações estão acontecendo das mais diversas formas, como, as graves conseqüências ocorridas pelo aquecimento global aos sistemas de produção agrícola e animal, e as catástrofes ocorridas em diversas partes do mundo. Trazendo a atualidade as manifestações, que no passado alertaram para a degradação e desequilíbrio do meio-ambiente e que hoje estão sendo percebidas.

Deve-se também reconhecer que vivemos em uma sociedade na qual é fundamental partir de uma boa formação e de um sólido conhecimento dos complexos problemas e potencialidades ambientais. Nossa sociedade deve se conscientizar de que o modelo vigente de crescimento afeta muito nosso planeta. Tem-se observado que a destruição da natureza, base da vida, através da contaminação e degradação dos ecossistemas crescem em um ritmo acelerado, motivo pelo qual se torna necessário reduzir o impacto ambiental para a obtenção de um desenvolvimento ecologicamente equilibrado a curto prazo para todo o planeta, sendo a educação ambiental, um elemento indispensável para a transformação da consciência dos alunos

Este estudo teve por objetivo, identificar como a Educação Ambiental vem sendo tratada em suas diferentes formas no Centro de Ciências Rurais da Universidade Federal de Santa Maria e com uma abordagem focada para o curso de Zootecnia no que se refere à educação formal. 


\section{MÉTODOLOGIA}

A pesquisa foi desenvolvida por meio da utilização de instrumentos qualitativos e quantitativos de coleta de dados, reunindo características de cunho exploratório e descritivo, para cumprir o objetivo de mensurar como a Educação Ambiental esta inserida no Centro de Ciências Rurais da UFSM (CCR), apontando condições, desafios e perspectivas para a ampliação de sua inserção no CCR.

A análise dos dados foi baseada nas diferentes tipologias de ensino, tomando como base as três distintas formas de educação sendo estas a educação formal, não formal e a educação formal. Para a análise da inserção da EA como educação formal foram pesquisados o Curso de Pós Graduação em Educação Ambiental, o curso de Zootecnia e os Laboratórios usados para as aulas práticas do curso de Zootecnia. A pesquisa foi delimitada em aprofundar a abordagem apenas para o curso de Zootecnia no que se refere à educação formal. Foi realizada uma análise dos meios de educação não formal existentes no CCR, sendo estes delimitados como os Projetos registrados no Gabinete de Projetos (GAP) do CCR voltados para a EA, o Fórum de Educação Ambiental, a Semana Acadêmica do Curso de Zootecnia e o Programa de Educação Sócio Ambiental Multicentros na UFSM e na Comunidade do Território Centro RS. A inserção da EA de como Educação Informal no CCR/UFSM foi analisada por meio das ações realizadas pela Comissão do Meio Ambiente, do Grupo Pet Zootecnia e da Empresa Floresta JR do Curso de Engenharia Florestal do CCR/UFSM.

Os dados foram coletados por meio de entrevistas a pessoas responsáveis pelas áreas estudadas, como coordenadores e integrantes de projetos e programas, chefe do Departamento de Zootecnia, responsáveis pelos laboratórios do Departamento de Zootecnia, observações, estudos sobre dados documentados, dados secundários bem como pesquisa bibliográfica.

\section{RESULTADOS E DISCUSSÃO}

\section{Educação ambiental formal no Centro de Ciências Rurais da UFSM}

Nas próximas seções será discutido se a Educação Ambiental (EA) está inserida e como acontece essa possível inserção, como Educação Formal no CCR/UFSM, por meio da análise do Curso de Pós Graduação em Educação Ambiental, do curso de Zootecnia e dos Laboratórios usados para as aulas práticas do curso de Zootecnia. A pesquisa foi delimitada em aprofundar a abordagem apenas para o curso de Zootecnia no que se refere à educação formal.

\section{Curso de Pós Graduação em Educação Ambiental}

O curso de especialização em EA da UFSM está vinculado ao CCR, e possui duas modalidades, sendo uma presencial e outra a distância, começou suas atividades no ano de 1996 quando foi aprovado pelo parecer 031/95 da Comissão de Ensino e Pesquisa CEPE. Este curso é uma das mais importantes ferramentas de educação formal em EA presente na UFSM, pois trata diretamente a EA. O curso proporciona a qualificação acadêmica aos profissionais das mais diversas áreas do conhecimento e que estão comprometidos com o ensino, pesquisa e extensão e que buscam a discussão crítica dos problemas ambientais na procura de soluções.

De acordo com o Projeto Político Pedagógico do Curso de Pós Graduação em Educação Ambiental da UFSM (PPPEA) o objetivo geral do Curso é oferecer subsídios técnico-pedagógicos a profissio- 


\section{REMOA}

nais das mais diversas áreas de conhecimento para atuar como multiplicadores ambientais em seus respectivos campos de ação. Isso deve ocorrer tratando temas referentes ao desenvolvimento de estudos dos problemas ambientais, provocados pelo homem, ressaltando que as práticas educativas ajudam a promover a sua sustentabilidade. O tratamento destes temas é parte da formação continuada do professor e de como ele pode apropriar-se das modificações que se transfiguram na sociedade, sem perder sua identidade enquanto educador. Os objetivos específicos do Curso de Pós Graduação em EA são três:

- Capacitar cientificamente profissionais para executar atividades de: Ensino, Pesquisa e Extensão na forma de trabalhos técnicos e práticos, trabalhando as questões ambientais na sua forma teórica, metodológica e aplicada;

- Proporcionar atualização dos profissionais, buscando uma ação holística na área ambiental, para sua aplicação na educação ambiental de forma: multi, inter, e trans-disciplinar. No sentido de proporcionar a transformação da contribuição isolada de cada docente, em programas diversos, em uma atividade integrada de reflexão constante, em relação à própria cientificidade de uma dada prática de pesquisa, e em relação aos resultados das diversas ciências, sem romper com a especificidade do olhar ecológico;

- Fornecer novas metodologias técnico-pedagógicas, para serem aplicadas no desenvolvimento local, regional e nacional, isto implica em satisfazer a demanda por pesquisa na área ambiental, oferecendo aos estudantes das mais diversas áreas da UFSM e de outras Universidades do estado do Rio Grande do Sul e demais estados, qualificação em seus estudos.

Segundo o PPPEA a integração dos diversos saberes: científico, social, político, cultural e econômico, em um enfoque interdisciplinar do meio ambiente, se processa através da construção de um modelo fundamentado na idéia de interação entre os diferentes fatores que incidem sobre um problema ambiental. É, portanto, um processo dinâmico, onde dois ou mais conceitos evoluem conjuntamente e conduzem à compreensão de um novo nível de complexidade. O que vem de encontro com Jacob (2003) onde este autor afirma que a dimensão ambiental configura-se crescentemente como uma questão que diz respeito a um conjunto de atores do universo educativo, potencializando o envolvimento dos diversos sistemas de conhecimento, a capacitação de profissionais e a comunidade universitária numa perspectiva interdisciplinar.

O curso em seu site possui um canal direto onde as monografias de conclusão de curso estão disponíveis a comunidade e também uma revista chamada Revista Monografias Ambientais (REMOA/UFSM).

Leff (2001) fala sobre a dificuldade de resolver os problemas ambientais e reverter suas causas sem que ocorra uma mudança nos sistemas de conhecimento. O PPPEA entra nessa idéia afirmando que é preciso compreender, então, que a EA faz parte de um método educativo multidimensional exigindo reflexões que conduzam ao diálogo e ao estabelecimento de interações entre os diversos componentes das disciplinas e do currículo deste curso, bem como, das suas áreas de concentração.

O PPPEA relata que são as trocas, de ações conjuntas, que proporcionam os espaços de socialização e construção, dentro do processo educativo, portanto, entende-se que a universidade deve ser lugar de mudança e não de reprodução do sistema vigente, devido seu caráter multidisciplinar, constituindo-se em um espaço privilegiado para o desenvolvimento de projetos que envolvam a questão ambiental. Jacobi (2003) fala que a realidade atual exige uma reflexão cada vez menos linear, e isto se produz na inter-relação dos saberes e das práticas coletivas que criam identidades e valores comuns e ações solidárias diante da reapropriação da natureza, numa perspectiva que privilegia o diálogo entre saberes. 


\section{REMOA}

Podemos perceber que a estrutura do PPPEA está de acordo com Sorrentino (1998) que chama a atenção para a necessidade de se articularem ações de educação ambiental baseadas nos conceitos de ética e sustentabilidade, identidade cultural e diversidade, mobilização e participação e práticas interdisciplinares.

\section{Educação ambiental no curso de Zootecnia da UFSM}

Segundo o Projeto Político Pedagógico do curso de Zootecnia da UFSM (PPPZ), o curso tem como objetivo geral formar profissionais cidadãos, cientificamente e tecnicamente capacitados para solucionar problemas nas áreas de sua competência: estimular a produção animal e de alimentos, aderir à biotecnologia, proteger o meio ambiente e se inserir no contexto social como indivíduos moderadores e transformadores.

O curso, além de metodologias demonstrativas (ex: aulas expositivas) buscará diversificação didático-pedagógicas que privilegiem a pesquisa e a extensão como instrumentos de aprendizagem, estimulando a atitude científica (PPPZ).

Está descrito no PPPZ que é área de atuação do Zootecnista formado pela UFSM a área de Ciências Ambientais onde o profissional irá atuar na produtividade animal considerando as conseqüências das diferentes ações com relação ao meio ambiente na tentativa de evitar os problemas em decorrência do descuido com as questões ambientais.

Segundo a proposta do PPPZ a interdisciplinaridade é um fator importante durante a formação acadêmica. Analisando o ementário do curso é possível observar que aspectos ligados a educação ambiental estão presentes no ementário de algumas disciplinas, como nas disciplinas de Solos e Produção Animal, Manejo e Fertilidade do Solo, Bioclimatologia, Qualidade e Sustentabilidade na Produção Animal e Suinocultura. Segundo Tristão (2004) essa inserção de assuntos sobre a EA revestem-se de um começo para se exercer a interdisciplinaridade, pois são trabalhos de busca.

O curso possui ainda na sua grade curricular, as disciplinas de Ciência do Ambiente e Gestão Ambiental, que estão diretamente relacionadas com a questão ambiental.

De acordo com Carneiro (1992) não há uma disciplina específica sobre a qual se fundamente o desenvolvimento da EA ela é multi e interdisciplinar. Todos os professores podem inserir e desenvolver a temática ambiental em suas disciplinas. O que corroba com a proposta do PPPZ e com a ementa do curso, onde a EA está inserida em várias disciplinas e ainda possui uma disciplina específica com maior ênfase a esse aspecto. Essa inserção da questão ambiental em disciplinas específicas vem de acordo com Velasco (2002) que afirma ser preferível ter ao menos um espaço garantido para a EA na forma de disciplina do que não termos nada em absoluto, além de observar que não ofertar conteúdos disciplinares relacionados à Educação Ambiental, na graduação, pode ser interpretado como a perda de espaços de reflexão que implica impossibilidade de novas propostas pedagógicas.

Podemos perceber que a proposta do PPPZ está com bom embasamento contemplando a EA na forma interdisciplinar e também com espaços reservados para ser trabalhada com maior especificidade, porém ainda há a preocupação de como essa interdisciplinaridade acontece na prática se ela se da de maneira efetiva. Outro aspecto é a oferta das disciplinas de Ciência do Ambiente e Gestão Ambiental ocorrer nos primeiros semestres do curso, sendo no segundo e terceiro semestre respectivamente, onde há a grande possibilidade de termos um público ainda imaturo que corre o risco de não ter a oportunidade de ao avançar do curso rever esses aspectos de extrema importância.

Segundo Pereira (2007) a EA na educação formal pode fomentar um espaço para reflexões principalmente sobre o lugar que os sujeitos ocupam na sociedade e a força que suas ações em conjun- 


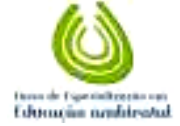

BOEMO \& HILIG, vol.(4), n4, p. 616-628, 2011. Monografias Ambientais

(e-ISSN: 2236-1308)

REMOA

to têm de inovar e de transformar, fato esse que antes não era percebido. $O$ autor ainda afirma que a EA deve ser crítica o suficiente para conseguir formar seres políticos e conseqüentemente ativos.

\section{Educação ambiental nos laboratórios do Departamento de Zootecnia utilizados para aulas práti- cas do Curso de Zootecnia.}

Os laboratórios pertencentes ao DZ são ferramentas utilizadas para serem ministradas as aulas práticas do curso de Zootecnia e de outros cursos do CCR que tem em sua grade curricular as disciplinas zootécnicas, nessa seção será discutida se EA está inserida nesses laboratórios, e como ela é realizada.

O DZ da UFSM possui dez laboratórios, destinados ao ensino, pesquisa e extensão, os laboratórios servem como uma extensão da sala de aula para os alunos terem a oportunidade de presenciarem na prática os ensinamentos teóricos recebidos em sala de aula. Os laboratórios vinculados ao DZ são: Laboratório de Apicultura, Avicultura, Bovinocultura de Corte, Bovinocultura de Leite, Laboratório de Cunicultura, Forragicultura, Peixes, Bromatologia e Ruminantes, Ovinocultura e Laboratório de Suinocultura.

Todos os laboratórios fornecem aos alunos orientações sobre sustentabilidade e sobre o manejo básico dos resíduos gerados pelo laboratório, seja esse resíduo de origem orgânica ou nãoorgânica. Segundo Jacobi (2003) a problemática socioambiental, ao questionar ideologias teóricas e práticas, propõe a participação democrática da sociedade na gestão dos seus recursos atuais e potenciais, assim como no processo de tomada de decisões para a escolha de novos estilos de vida e a construção de futuros possíveis, sob a ótica da sustentabilidade ecológica e a eqüidade social.

O Laboratório de Suinocultura possui uma linha de pesquisa preocupada com o impacto que a atividade causa ao meio ambiente que é a implantação de uma unidade demonstrativa de manejo e reutilização da água residuária do setor. O projeto é intitulado como: Reuso de água residuária da biofiltragem na suinocultura: aspectos zootécnicos, ambientais e econômicos. Esse projeto tem o objetivo de desenvolver um sistema para o reuso da água proveniente da suinocultura bem como avaliar o impacto econômico e social do reuso da água residuária da suinocultura.

O Laboratório de Avicultura esta integrado com a Comissão do Meio Ambiente (CMA) e por meio de sua ação que busca o reaproveitamento de papel, onde a CMA fez a aquisição de uma fragmentadora de papéis para triturar documentos sendo este resíduo reaproveitado para servir como cama para os pintos no Laboratório de Avicultura. O material utilizado como cama aviária, no período de produção das aves no LAVIC é a maravalha que ao final do lote esse resíduo é recolhido e destinado a adubação hortifrutigranjeira por pessoas terceirizadas.

O Laboratório de Bovinocultura de Corte, preocupado com o impacto ambiental que a atividade exerce, desenvolveu no ano de 2010 um projeto estudando a viabilidade da adubação orgânica, utilizando dejetos animais como alternativa na adubação de solos agrícolas. O objetivo da pesquisa foi de obter maiores informações sobre o aproveitamento da adubação orgânica, proveniente de dejetos suínos e bovinos, e o potencial do milho como silagem.

No Laboratório de Ovinocultura os dejetos dos animais, que poderiam ser um contaminante ambiental são recolhidos e destinados a adubação orgânica por pessoas terceirizadas, o que diminui o possível risco ambiental gerado pela atividade, no laboratório.

O Laboratório de Piscicultura, e de Bromatologia e Ruminantes que possuem laboratórios com o uso rotineiro de produtos químicos, a destinação dos resíduos químicos é feita por uma empresa terceirizada e especializada no tratamento de resíduos químicos. 


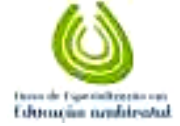

BOEMO \& HILIG, vol.(4), $n^{\circ} 4$, p. 616-628, 2011. Monografias Ambientais

(e-ISSN: 2236-1308)

REMOA

Ainda há muito espaço para a inserção da EA nos laboratórios do DZ, ainda mais por se tratar de atividades que possuem alto potencial de degradação do meio ambiente. De acordo com Jacobi (2003) o desafio que está colocado é o de não só reconhecer, mas estimular práticas que reforcem a autonomia e a legitimidade de atores sociais que atuam articuladamente numa perspectiva de cooperação. O saber ambiental requer uma problematização dos paradigmas do conhecimento, das práticas de pesquisa e das ideologias da teoria e da prática (JACOBI 2004).

\section{Educação ambiental não formal no Centro de Ciências Rurais da UFSM}

Nas próximas seções será discutido se a EA está inserida e como acontece essa possível inserção, na classificação de Educação Não Formal no CCR/UFSM. Para isso foi realizada uma análise dos meios de educação não formal existentes no CCR, sendo estes delimitados como os Projetos registrados no Gabinete de Projetos (GAP) do CCR voltados para a EA, o Fórum de Educação Ambiental, a Semana Acadêmica do Curso de Zootecnia e o Programa de Educação Sócio Ambiental Multicentros na UFSM e na Comunidade do Território Centro RS.

\section{Projetos registrados no Gabinete de Projetos (GAP) do CCR voltados para a educação ambiental}

O Gabinete de Projetos (GAP) atua de forma integrada com a Direção do CCR e com as PróReitorias da UFSM no sentindo de informatizar e divulgar as fontes e as formas de busca de recursos necessários ao desenvolvimento das atividades de pesquisa e extensão da comunidade cientifica. Nessa seção será abordada se a EA está presente nos projetos registrados do GAP do CCR.

No GAP há 36 projetos de pesquisa registrados nos quais a EA aparecem nos títulos, salientando que pode haver outros projetos que abordem a EA em seu conteúdo, porém sem as palavras EA estarem presente no título. Para a realização dessa pesquisa foram analisados apenas os projetos que possuem EA no título do projeto, pois a busca em todos os projetos seria de difícil mensuração para a realização dessa pesquisa.

Dos 36 projetos registrados no GAP que possuem EA no titulo 15 já foram concluídos, três cancelados, seis estão aguardando os tramites para conseguirem o registro e nove estão em andamento. Entre os nove projetos que estão em andamento sete tem sua classificação principal como projetos de extensão universitária e dois como projetos de pesquisa.

Dos projetos que estão em andamento, há dois que foram renovados e são os mais antigos com o inicio no ano de 2008 , são projetos que tem sua classificação principal como projetos de extensão universitária e são também os projetos que possuem maior número de participantes.

Outro projeto que se enquadra na classificação principal como projeto de extensão universitária e traz um tema muito interessante é o projeto intitulado como: Educação Ambiental Objetiva para os Três Níveis de Ensino: Fundamental, Médio e Superior. Este projeto visa conhecer o grau de avanço intelectual dos estudantes dos ensinos fundamental, médio e superior com relação aos fatores ambientais ligados aos recursos Naturais Renováveis.

Dentre os projetos registrados no GAP merece destaque o Fórum de Educação Ambiental que esta vinculado a Comissão do Meio Ambiente e será discutido a seguir.

Os projetos são ferramentas de fundamental importância para a ascensão da EA. Segundo CarvaIho (2001) o diversificado rol de atividades e projetos de desenvolvimento impulsionados pelas atividades de extensão vem em resposta as novas demandas geradas pela transição ambiental.

Num contexto marcado pela degradação permanente do meio ambiente e do seu ecossistema, a problemática envolve um conjunto de atores do universo educativo em todos os níveis, potencializando o engajamento dos diversos sistemas de conhecimento, a capacitação de profissionais e a comunidade universitária numa perspectiva interdisciplinar (JACOBI 2005). 
BOEMO \& HILIG, vol.(4), n4, p. 616-628, 2011. Monografias Ambientais $\quad$ (e-ISSN: 2236-1308)

REMOA

\section{Fórum de Educação Ambiental}

O Fórum de Educação Ambiental é um projeto que faz parte da Comissão do Meio Ambiente, registrado no GAP do CCR. O Fórum de Educação Ambiental teve inicio no ano de 2000 e possui uma reunião mensal de quatro horas, sendo estas realizadas no CCR, tendo como público alvo a sociedade em geral e os temas centrais da reunião voltados para o Meio Ambiente, Educação Ambiental e Sustentabilidade. Nas reuniões são convidados palestrantes que desenvolvem as temáticas propostas, seguidas de debates e de conclusão/fechamento de idéias/propostas a serem encaminhadas conforme o caso.

O Fórum de Educação Ambiental tem como objetivos específicos:

- Auxiliar na des(re)construção das representações de ambiente e problemas ambientais e sustentabilidade;

- Auxiliar profissionais a repensar sua prática, reorientando procedimentos e ações visando uma melhor atuação na natureza e na sociedade;

- Promover e manter sistematicamente um espaço de discussão sobre as questões ambientais na UFSM, visando reunir pessoas em torno de um ideal comum que é o de melhorar qualidade de vida individual e coletiva.

Para os anos de 2010/2011 tem como temas previstos para as reuniões: Psicologia e Meio Ambiente,Saúde e Meio Ambiente, Economia e Meio Ambiente, Política e Meio Ambiente, SociedadeCultura e Meio Ambiente e Arte e Meio Ambiente.

È possível perceber que os enfoques das reuniões do Fórum estão além de apenas a preocupação com o meio ambiente e sim também com a relação das pessoas como meio em geral na qual elas estão inseridas. A preocupação do Fórum vem de encontro com a preocupação de Morin (2002) que diz que as instituições não estão preparadas e não preparam os indivíduos para lidar com várias questões, dentre elas o multiculturalismo, a diversidade e homogeneização das culturas e os conflitos que estas questões provocam.

Apesar das reuniões do Fórum de Educação Ambiental ser uma iniciativa do CCR e acontecerem nos prédios do CCR é possível observar que o público que participa das reuniões é bastante diversificado, oriundo de outros centros de ensino da UFSM. Isso demonstra que a preocupação com o meio ambiente atravessa fronteiras físicas e atrai a atenção de um público de origem diversa não estando restrita apenas a comunidade do CCR.

\section{Semana acadêmica do curso de Zootecnia da UFSM}

A semana acadêmica do curso de Zootecnia é oferecida anualmente e está dentro das Atividades Complementares de Graduação (ACG) que o curso oferece, sendo que o acadêmico do curso de zootécnico deve obrigatoriamente participar de no mínimo duas semanas acadêmicas durante 0 curso. A semana acadêmica é organizada pelo Diretório Acadêmico o Curso de Zootecnia (DAZ), sendo o DAZ responsável pela programação técnica do evento e pela escolha dos temas a serem abordados. Os temas a serem abordados geralmente vêm de encontro com a demanda dos alunos do curso e pela demanda de mercado, assuntos que estão em pauta no momento.

Analisando a programação das três ultimas edições do evento na UFSM é possível constatar que a educação ambiental não esteve inserida na programação, isso provavelmente acontece pela valorização do tecnicismo existente na área. É possível perceber que isso acontece dentro do curso e reflete nas preferências dos acadêmicos que acabam por privilegiar o tecnicismo na área zootécnica em detrimento da sustentabilidade e da preocupação com o meio ambiente. 


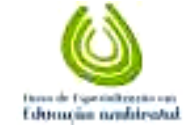

\section{BOEMO \& HILIG, vol.(4), n4, p. Monografias Ambientais}

(e-ISSN: 2236-1308)

\section{REMOA}

Jacobi (2003) diz que o entendimento sobre os problemas ambientais se dá por uma visão do meio ambiente como um campo de conhecimento e significados socialmente construído, que é perpassado pela diversidade cultural e ideológica e pelos conflitos de interesse. A semana acadêmica é uma jornada que perfaz 40 horas e sendo que é uma atividade obrigatória para os acadêmicos do curso, seria um momento em que a EA poderia estar inserida, onde poderiam ser debatidos alguns dos problemas relacionados à EA com um espaço garantido. Essa preocupação infelizmente ainda não está presente na mentalidade dos acadêmicos que organizam o evento.

\section{Educação Sócio Ambiental Multicentros na UFSM e na Comunidade do Território Centro RS}

O programa de Educação Sócio Ambiental Multicentros na UFSM e na Comunidade do Território Centro RS é um programa registrado no GAP do CCR e possui apoio do Programa de Extensão Universitária (ProExt). O ProExt é um programa do governo Federal criado em 2003 e tem o objetivo de apoiar as instituições públicas de ensino superior no desenvolvimento de programas ou projetos de extensão que contribuam para a implementação de políticas públicas. O ProExt abrange a extensão universitária com ênfase na inclusão social, sendo que o programa de Educação Sócio Ambiental Multicentros na UFSM e na Comunidade do Território Centro RS se enquadra nessa perspectiva e foi aprovado em 2011.

A proposta do programa de Educação Sócio Ambiental Multicentros na UFSM e na Comunidade do Território Centro RS é de promover o debate das temáticas socioambientais que perpassam a formação dos diversos profissionais, os projetos de pesquisa e extensão, contando com a contribuição das diversas áreas do conhecimento.

O programa possui uma agenda onde são realizadas periodicamente reuniões com os integrantes do programa e também promove seminários abertos a comunidade em geral. O primeiro seminário do programa foi realizado no dia 16 de junho de 2011 e teve como tema Do ambiente ao socioambiente, e aconteceu no auditório do CCR.

Programas como o de Educação Sócio Ambiental Multicentros na UFSM e na Comunidade do Território Centro RS, são de fundamental importância para a educação ambiental (EA), pois é uma maneira de trazer a EA com uma visão multidisciplinar para a comunidade acadêmica, rompendo os limites das salas de aula e os "muros" que se erguem em relação aos campos do conhecimento, promovendo assim uma integração de diferentes visões e percepções sobre a EA e sua importância para a sociedade.

De acordo com Guimarães, (1995) mais do que uma realidade, a EA tornou-se uma grande necessidade e apresenta uma nova dimensão a ser incorporada ao processo educacional, trazendo toda uma recente discussão sobre as questões ambientais, e as conseqüentes transformações de conhecimento, valores e atitudes diante de uma nova realidade a ser construída.

\section{Educação ambiental informal no Centro de Ciências Rurais da UFSM}

Nas próximas seções será discutido se a EA está inserida e como acontece essa inserção como Educação Informal no CCR/UFSM, por meio da análise das ações realizadas pela Comissão do Meio Ambiente, do Grupo Pet Zootecnia e da Empresa Floresta JR do Curso de Engenharia Florestal do CCR/UFSM.

\section{Comissão do Meio Ambiente do CCR}

A comissão de Meio Ambiente do Centro de Ciências Rurais existe desde 2003 e desenvolve uma série de programas. Entre outros projetos, merece destaque o Fórum Permanente de Educação 
REMOA

Ambiental, no qual são realizadas reuniões mensais, em que se discutem temáticas relacionadas ao meio ambiente e a sustentabilidade.

A Comissão do Meio Ambiente do CCR, segundo seu regimento tem por objetivo auxiliar na (re) construção das representações de ambiente, problemas socioambientais e sustentabilidade, buscando promover a reorientação de procedimentos e ações profissionais cotidianas, visando uma melhor atuação na universidade e na sociedade.

A Comissão do Meio Ambiente do CCR possui uma equipe composta por nove membros, dentre estes professores, técnicos em educação, alunos de graduação e pós graduação ligados ao CCR. Essa comissão se reúne quinzenalmente para estudar ações relacionadas à sustentabilidade e a educação ambiental no CCR.

As ações são planejadas para serem implementadas a curto, médio e longo prazo. A Comissão do Meio Ambiente do CCR possui parceria com a Assessoria de Comunicação Integrada (ASCOM), para a realização de campanhas permanentes voltadas para a sensibilização da comunidade do CCR para os problemas ambientais. Dentre as ações já realizadas e implementadas pela Comissão do Meio Ambiente do CCR estão:

- $\quad$ Lançamento da Campanha "Como posso melhorar meu ambiente de trabalho e estudos" em conjunto com a ASCOM;

- $\quad$ Aquisição e instalação de coletoras de resíduos (papéis e plásticos) em todas as salas de aula dos prédios 42 e 44 do CCR;

- $\quad$ Confecção e distribuição de canecas, presente de aniversário, em conjunto com a ASCOM, para os docentes e técnicos administrativos, com o objetivo de reduzir o consumo de copos descartáveis;

- $\quad$ Aquisição de uma fragmentadora de papéis para triturar documentos e reaproveitamento de seus resíduos para cama dos pintos no Laboratório de Avicultura;

- $\quad$ Atualização e distribuição do Guia de Descarte de Resíduos a comunidade do Centro, em Conjunto com a Assessoria de Comunicação;

- $\quad$ Projeto-piloto para reaproveitamento da água da chuva, no prédio 42, o pré-projeto está sendo elaborado pela Pró Reitoria de Infra-estrutura (PROINFRA);

As políticas ambientais e os programas educativos relacionados à conscientização da crise ambiental demandam crescentemente novos enfoques integradores de uma realidade contraditória e geradora de desigualdades que transcendem a mera aplicação dos conhecimentos científicos e tecnológicos disponíveis (JACOBI 2004).

A Comissão do Meio Ambiente e suas ações são ferramentas de difusão da EA de grande relevância dentro da UFSM e especialmente dentro do CCR. Segundo Jacobi (2003) a educação ambiental que tem sido desenvolvida no país é muito diversa, e a presença dos órgãos governamentais como articuladores, coordenadores e promotores de ações é ainda muito restrita, sendo de extrema importância atividades como a da Comissão do Meio Ambiente que atua como disseminadora da EA.

A Comissão do Meio Ambiente traz consigo também a preocupação com a interação das pessoas com o ambiente de trabalho o que corroba com Jacobi (2003) que fala que a educação ambiental deve destacar os problemas ambientais que decorrem da desordem e degradação da qualidade de vida nas cidades e regiões. Carvalho (2001) afirma que o mais desafiador é evitar cair na simplificação da EA e superar uma relação pouco harmoniosa entre os indivíduos e o meio ambiente através de práticas localizadas e pontuais, muitas vezes distantes da realidade social de cada aluno. 
REMOA

\section{Monografias Ambientais (e-ISSN: 2236-1308)}

\section{Educação ambiental no Grupo PET Zootecnia}

O Grupo PET Zootecnia desenvolve várias atividades na área de pesquisa, ensino, extensão e atividades coletivas ligadas ao CCR. Está dentre as atividades desenvolvidas pelo grupo PET Zootecnia o Projeto Ecopet. A preocupação desse projeto está direcionada à grande quantidade de lixo produzida, e o correto funcionamento do sistema de coleta seletiva, visando diminuir a poluição ambiental. Em vista disso, os grupos PET's da UFSM se uniram e estão desenvolvendo o Projeto Ecopet - Coleta Seletiva. Suas atividades iniciaram no primeiro semestre de 2010 e têm como principal objetivo formar uma equipe, subprogramas, que gerem a disseminação da EA dentro da instituição, tendo em vista a minimização do impacto gerado pelos resíduos produzidos, além de promover uma sensibilização da comunidade universitária a respeito da problemática do lixo.

Os objetivos do Ecopet são de aperfeiçoamento no sistema de coleta seletiva de material reciclável da UFSM, facilitar o processo de triagem para os catadores e aumentar o reaproveitamento do material potencialmente reciclável.

A inserção do grupo Pet em um projeto preocupado com a preservação do meio ambiente demonstra que os acadêmicos estão atentos as questões ambientais e a sua importância e também isso pode ser um indicativo que o meio o qual estes alunos estão inseridos pode estar agindo como influencia ou incentivo para esse tipo de ação, pois segundo Higuchi \& Azevedo (2000) ao se propor qualquer ação, seja ela preventiva, educativa ou terapêutica, tem-se em primeiro lugar que saber as teorias, conceitos e representações sobre o tema com o qual se pretende trabalhar. Ao interpretar o que esse autor afirma podemos pressupor que os integrantes desse grupo estão inseridos no contexto ambiental e que possuem embasamento sobre o assunto o que se torna uma importante ferramenta para trabalhar a EA.

\section{Empresa Floresta JR do curso de Engenharia Florestal do CCR/UFSM}

A Floresta Jr. é a empresa Júnior do curso de Engenharia Florestal da Universidade Federal de Santa Maria - UFSM. Formada por alunos de graduação do curso, conta com a orientação e supervisão técnica dos professores e o apoio da estrutura de um dos maiores centros de formação de Engenheiros Florestais do país.

Através de atividades como palestras, educação ambiental, cursos, promoção de eventos e atividades empresariais, proporciona a aplicação prática de conhecimentos relativos à área de formação profissional do Engenheiro Florestal. Prestam serviços nas áreas de Inventário Florestal, Silvicultura, Paisagismo, Ecologia, Projetos Ambientais, entre outros.

A empresa possui um site em que é possível o visitante ter acesso direito ao site Ambiente Brasil (http://www.ambientebrasil.com.br) onde é possível encontrar diversas informações sobre as questões ambientais.

O grupo Empresa JR traz diretamente em sua temática a EA, isso acontece como no grupo Pet que nos faz refletir sobre a influência do meio sobre as tomadas de decisões em relação à escolha dos temas a serem trabalhados. De acordo com Ruscheinsky (2003) a compreensão de meio ambiente de cada indivíduo, enquanto membro de um grupo social consolida uma representação social, portanto, o ponto de partida para o trabalho com educação ambiental deve ser a própria representação do educador e das pessoas envolvidas nesse processo.

\section{CONCLUSÕES}

A Educação Ambiental (EA) busca fazer com que o ser humano, compreenda o meio ambiente e sua natureza complexa onde este está inserido e atuando como agente transformador do mesmo, 
REMOA

BOEMO \& HILIG, vol.(4), n4, p. 616-628, 2011. Monografias Ambientais $\quad$ (e-ISSN:2236-1308)

lembrando que estas transformações são resultantes das constantes interações entre os aspectos físicos, biológicos culturais e sociais. Além de resolver conflitos ou preservar a natureza através de intervenções pontuais a EA entende que a transformação dos grupos humanos com o meio ambiente esta inserida dentro do contexto da transformação da sociedade (JACOBI, 2005). Essa transformação só terá condições de acontecer se explorarmos a EA em suas diferentes formas de educação, a formal, não formal e informal.

Com esse estudo houve a possibilidade de verificar como a Educação Ambiental está presente no Centro de Ciências Rurais da Universidade Federal de Santa Maria. Foi possível constatar que há várias vertentes ligadas a EA no CCR as quais levam sob as diferentes perspectivas de educação a educação ambiental ao CCR.

O CCR se põe em destaque em relação à EA por possuir um curso de Pós Graduação em Educação Ambiental, e que periodicamente qualifica profissionais para trabalharem diretamente com as questões ambientais. Porém este curso encontra-se de certa forma restrito aos alunos aos quais a ele estão vinculados, e a comunidade acadêmica com interesse já formado sobre a área ambiental, sendo que este poderia realizar atividades de expansão dos conhecimentos sobre EA para a comunidade do CCR e/ou comunidade em geral.

No estudo sobre o curso de zootecnia foi possível observar que dentro do Projeto Político Pedagógico do mesmo a EA está presente em algumas disciplinas com um enfoque maior e em outras de maneira transversal, porém fica ainda o questionamento de como esse tema vem sendo abordado e qual a importância que ele representa para os alunos. Ainda referente ao curso de zootecnia vale ressaltar o papel dos Laboratórios que são utilizados como extensão da sala de aula, estes por sua vez possuem muito espaço para abordar a educação ambiental de forma prática onde o aluno pode vislumbrar os aspectos ligados a EA e a uma criação animal especifica. Porém o que ocorre é uma deficiência nesse quesito, pois os laboratórios estão mais focados para a parte técnica da produção o que acarreta em um déficit na área ambiental. Salvo algumas exceções como o caso do Laboratório de Suinocultura que está com um projeto de relevada importância para a EA, e que servirá de exemplo sobre EA, não apenas para os envolvidos na pesquisa, mas também para as próximas gerações de alunos de CCR.

Iniciativas e ações como a Comissão do Meio Ambiente que atua de maneira efetiva buscando a sensibilização da comunidade para as questões ambientais são de extremo valor na sociedade em que vivemos onde muitas vezes o saber tecnicista acaba por sombrear a responsabilidade que a sociedade deve dispensar ao meio ambiente.

E possível vislumbrar que havendo a ligação entre a educação formal, não formal e educação informal que ocorre no CCR o somatório representa um saldo de certa forma satisfatório da EA no CCR. Mas para isso é necessário que as vertentes já existentes de EA se expandam que surjam novas iniciativas voltadas para a EA e que ocorra uma valorização da EA nos currículos dos cursos pertencentes ao CCR. Também é importante salientar a importância da integração das ações ligadas a EA no CCR e na UFSM, pois assim é possível que haja uma fortificação da EA e sensibilizando de forma mais efetiva a comunidade sobre a importância do tema. 
BOEMO \& HILIG, vol.(4), n4, p. 616-628, 2011. Monografias Ambientais $\quad$ (e-ISSN: 2236-1308)

REMOA

\section{REFERENCIAL TEÓRICO}

CARNEIRO, N. S. Educação Ambiental - Livro do Professor. Fundação Instituto Estadual de Florestas. Rio de Janeiro: IEF: REDUC, 1992.

CARVALHO, I. C. M. Qual educação ambiental? Elementos para um debate sobre educação ambiental e extensão rural. Agroecologia e Desenvolvimento Rural Sustentável. Porto Alegre, v.2, n.2, abr./jun.2001.

GUIMARÃES, M. A dimensão ambiental na educação. 6ạed. Campinas, SP: Papirus, 1995.

HIGUCHI ,M. I. G.; AZEVEDO, G. C. de. Educação como processo na construção da cidadania ambiental. Revista brasileira de educação ambiental. Brasilia,2004, $n^{\circ}$ zero.

JACOBI, P. Educação Ambiental: o desafio da construção de um pensamento crítico, complexo e reflexivo. Educação e Pesquisa, São Paulo, v. 31, n. 2, p. 233-250, maio/ago. 2005.

JACOBI. P. Revista brasileira de educação ambiental. Brasilia,2004, nzero.

JACOBI, P. Educação ambiental, cidadania e sustentabilidade. Cadernos de Pesquisa, n. 118, 2003.

JACOBI, P. Educação Ambiental: o desafio da construção de um pensamento crítico, complexo e reflexivo. Educação e Pesquisa, São Paulo, v. 31, n. 2, p. 233-250, maio/ago. 2005.

LEFF, E. Epistemologia ambiental. São Paulo: Cortez, 2001.

MORIN, E. A religação dos saberes: $\mathbf{O}$ desafio do século XXI. Tradução e notas Flávia Nascimento, 2a ed. Rio de Janeiro: Bertrand Brasil, 2002.

PEREIRA, K.A.B.; BITTAR, M.; GROGOLIA, J.A.G.; Transversalidade e a interdisciplinaridade em educação ambiental: Uma reflexão dentro da escola. In: VII Jornada do HITEDBR, 2007, Campo Grande. A organização do trabalho didático na história da educação: caderno de resumos da VII Jornada do HITEDBR - História, Sociedade e Educação no Brasil. Campo Grande : UNIDERP, 2007. p. 152-153.

RUSCHEINSKY. A. Sociologia das representações sociais e a educação ambiental. Contrapontos - volume 3 - n. 1 - p. 81-95 - Itajaí, jan./abr. 2003.

SORRENTINO, M. A educação ambiental no Brasil. In: JACOBI, P. et al. (orgs.). Educação, meio ambiente e cidadania: reflexões e experiências. São Paulo: SMA.1998.

TRISTÃO, M. Revista brasileira de educação ambiental. Brasilia,2004, nºero.

VELASCO, S. L. Algumas reflexões sobre a PNEA (Política Nacional de Educação Ambiental, Lei no9795 de 27/04/1999). Revista de Educação Ambiental da FURG, v.8, jan/jun. 2002. 